\title{
Growth Studies.
}

\section{A Quantitative Study of the Growth of Roots.}

\author{
J. H. PRIESTLEY and A. F. C. H. EVERSHED.
}

With five Tables and six Figures in the Text.

Contents.



\section{INTRODUCTION.}

DRING the last few years an extensive re-exploration of the problem of growth has taken place in which quantitative methods have been widely employed. We shall not attempt any summary of this work, as the present state of our knowledge has recently been presented very fully, especially in a series of papers by Briggs, Kidd, and West ( 3 and II).

Modern quantitative studies of plant growth are mainly based upon data as to changes in volume or length, whilst animal physiologists measure the growth of animals in terms of increase or decrease in length. This difference in attack is simply determined by the nature of the experimental material. Any investigator who has made efforts to record the growth of a baby or any other active young animal will know that length measurements demand a more than expert manipulation. On the other hand, if plant weights are to be significant, they must be dry weight determinations, and then the possibility of the progressive record of the growth of the same individual plant is removed.

Quantitative work upon the growth of animals appears to have been more fruitful in interpretation, and the reason seems to be that the records are of increase in mass and not in area or length. With the plant, change

[Annals of Botany, Vol. XXXVI. No. CXLII. April, 1922.] 
in form or size may be the expression of such subsidiary influences as intake and retention of water rather than of cumulative increase in living substance resulting from constructive metabolism. The aim of the work now presented was to obtain data for plant growth based upon mass measurements, with a view to seeing if the subsequent analysis of such data would be of value in throwing any light upon the inner.mechanism of growth.

\section{Experimental Material and Methods.}

\section{Choice of Material.}

Need for quantitative data seems to have become apparent to many workers recently, and from Cambridge (Briggs, Kidd, and West (3)), the Imperial College (Gregory (4)), and Rothamsted (Brenchley (2)) valuable results have been published since our experiments began in the summer of 1920. Most of these figures refer either to the growth of the whole plant or to the growth of leaves.

In choosing our experimental material it was necessary to bear in mind the fact that the leaf area represents the proportion of the plant engaged in the manufacture of food from raw materials. Figures giving an increase in leaf area would be expected to demonstrate the existence of an exponential law, because, as V. H. Blackman (1) has recently pointed out, increase in mass is directly connected with increase in photosynthetic area. Such an exponential relation between mass increase and time would depend upon a different train of circumstances from that connecting animal growth with time.

In order, therefore, to find out if a similar relationship between growth and time existed in the case of plants, attention was restricted to roots, where increase in manufacturing surface does not directly follow upon increase in mass, and where conditions more approximate to those obtaining in experiments with animals. Seedlings were not used for the preliminary work, on account of the difficulty of securing a uniform start, as germination involves a number of factors, including the resistance offered by the seed-coat, its gradual decomposition by bacteria, the original rate of entry of water, \&c. These obstacles were all removed by the decision to obtain data as to the production of roots upon cuttings.

\section{Experimental Method.}

In this work, first with Tradescantia Zebrina and later with tomatoes (Solanum Lycopersicum), we endeavoured to obtain uniformity of conditions between the cuttings of each set of experiments. The cuttings, taken from plants grown in the same greenhouse, were of approximately equal weight, and were all started at the same time. At definite time intervals, the root production was measured in terms of wet weight, and then of dry weight. 
Generally ten determinations were made on each occasion, and the probable errors estimated (Wood (12)).

We are aware that these experiments are on a relatively small scale, but circumstances make it impossible for us to extend their scope appreciably. However, with regard to the experimental results and their value as a basis for new conclusions, it must be noted that the significant feature of the curves appears in every set of figures and in every case is associated with the same phenomenon. This characteristic feature remains when full allowance is made for the calculated probable error of the data, at the critical points of the curves.

We hope that later further investigations, with increased experimental facilities, will permit of our conclusion receiving critical revision.

\section{Experimental Results.}

A summary of the results of our experiments will be found in the following tables and curves (Figs. I-4). Brief details as to the conditions under which each set of growth data were obtained are given. The most significant figures are given by the Tradescantia experiments, and reference to the tables shows that this material has yielded much more uniform results and that the experimental error is relatively small.

Data obtained from the experiments with tomatoes, however, are valuable in that they show, as the most striking features in a somewhat erratic curve (Fig. 4), the same characteristic points as in the case of Tradescantia.

\section{Experiments with Tradescantia.}

Series $I$. The cuttings were started on June 5,1920 , and were taken from plants in the greenhouse at Weetwood Hall and grown in empty flowerpots which stood inverted in dishes of water. The cuttings selected were as uniform as possible, their weights varying between 2.5 and 2.8 grammes, and the number of leaves on each varying from 5 to 8 . Ten cuttings were placed in each pot, and there were 20 pots in all. At intervals, one shoot was taken from each pot, and the roots were removed with a sharp knife, dried on blotting-paper, then weighed, dried at $100^{\circ} \mathrm{C}$. and weighed again. No roots were visible on the cuttings until the night of Thursday, June Io, and the first estimations of root-weight were made on June I4. Subsequently the remaining cuttings were taken at various dates, but the last twenty not until July 5 .

The dry weights and wet weights of the twenty cuttings were recorded individually, and then the mean weight and probable error calculated.

In the following table, only the mean weights and probable errors are given from consideration of space; for the same reason, temperature and humidity records of the greenhouses are not given, though they are available, 
together with full notes as to weather conditions during the time of the experiment.

TABle I. Tradescantia, Series I (see Fig. I).

$\begin{array}{ccc}\begin{array}{c}\text { Number of } \\ \text { days' growth. }\end{array} & \begin{array}{c}\text { Mean wet weight } \\ \text { of roots. } \\ \text { grm. }\end{array} & \begin{array}{c}\text { Mean dry weight } \\ \text { of roots. } \\ \text { grm. }\end{array} \\ 9 & 0.07 \pm 0.01 & 0.004 \pm 0.001 \\ \text { II } & 0.15 \pm 0.01 & 0.009 \pm 0.002 \\ \text { I2 } & 0.17 \pm 0.03 & 0.011 \pm 0.002 \\ \text { I3 } & 0.19 \pm 0.03 & 0.015 \pm 0.003 \\ \text { I4 } & 0.21 \pm 0.03 & 0.018 \pm 0.003 \\ \text { I7 } & 0.21 \pm 0.04 & 0.019 \pm 0.003 \\ \text { I9 } & 0.31 \pm 0.07 & 0.023 \pm 0.004 \\ 23 & 0.42 \pm 0.10 & 0.041 \pm 0.009 \\ 29 & 0.56 \pm 0.10 & 0.045 \pm 0.011\end{array}$

Series $I I$. In this series, the cuttings were grown separately in bottles of about 600 c.c. capacity. The bottles were filled with the three-salt

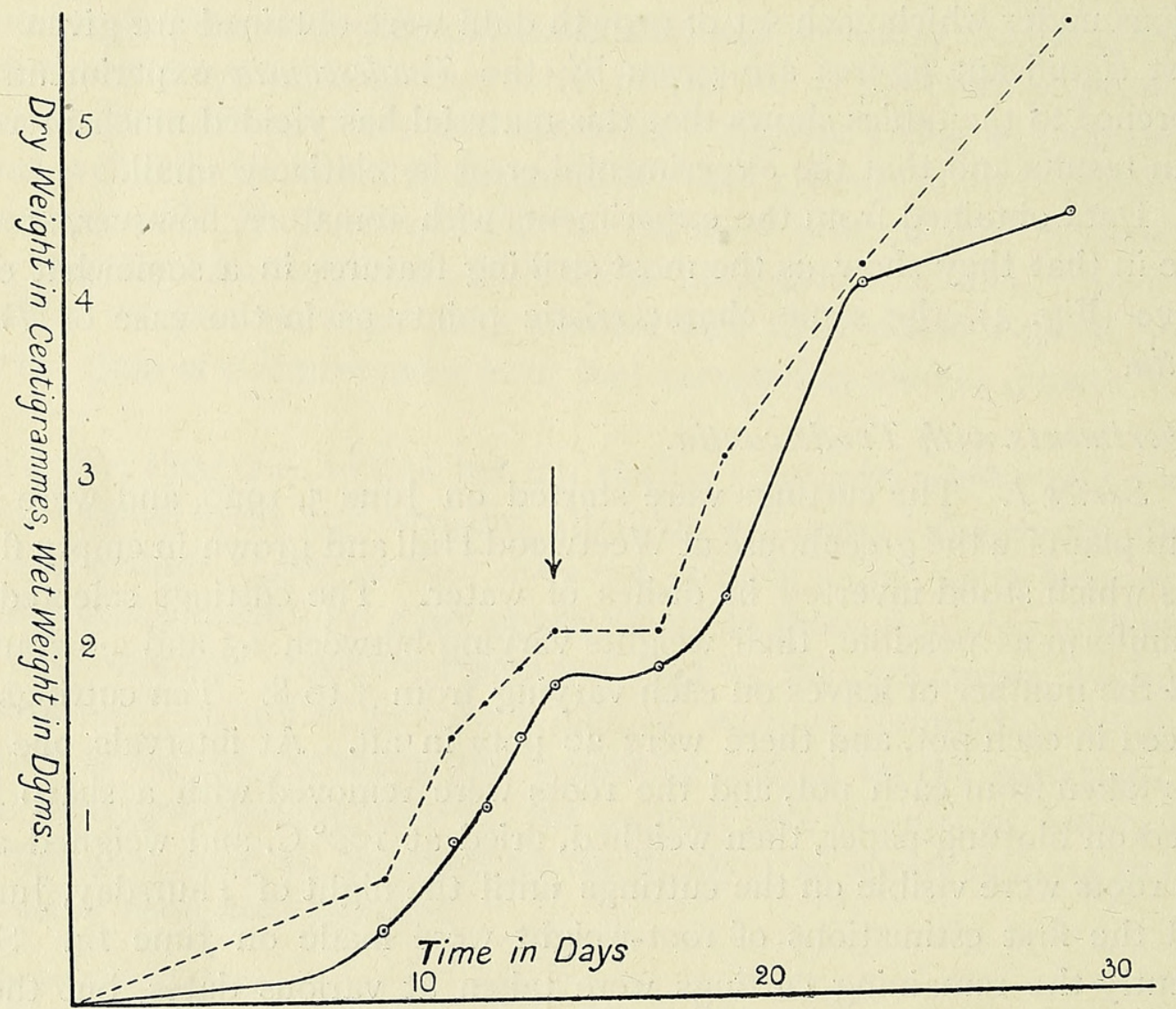

FIG. I. The increase in weight of roots on cuttings of Tradescantia. The dotted line gives the data for wet weight on a reduced scale. The arrow shows when secondary roots appeared.

solution found by Shive (10) to be most suitable in his investigation of waterculture methods. Gram-molecular solutions were made up of potassium dihydrogen phosphate, magnesium sulphate, and calcium nitrate. These 
solutions were kept in large stock aspirator bottles, which were permanently connected to burettes with three-way taps.

To each 600 c.c. bottle were added :

$$
\begin{aligned}
& \text { I0. } 8 \text { c.c. } \mathrm{KH}_{2} \mathrm{PO}_{4}, \mathrm{M} / \mathrm{I} \text { ) } \\
& \left.\begin{array}{l}
3 \cdot 0 \text { c.c. } \mathrm{Ca}\left(\mathrm{NO}_{3}\right)_{2} \mathrm{M} / \mathrm{I} \\
9 \cdot 0 \text { c.c. } \mathrm{MgSO}_{4} \mathrm{M} / \mathrm{I}
\end{array}\right\}
\end{aligned}
$$

and the bottles were then filled up to the neck with tap-water.

To each bottle were added seven drops of a fine suspension of ferric phosphate $(0.2 \mathrm{grm}$. in 100 c.c. distilled water). The bottles in this experiment were placed in a specially constructed lead-lined wooden trough, in which they stood immersed in water above the shoulders; the necks protruded through holes in black paper so that the roots developed in the dark. The water in the trough was kept continually flowing, and throughout the experiment the temperature remained very constant. The trough was placed on a laboratory table in a room with a glass roof, through which the cuttings obtained very satisfactory illumination. In warm weather the floor and table were sprayed several times daily to prevent the atmosphere from becoming too dry, and the plants throughout the experiment remained very healthy.

II 2 bottles were accommodated in the trough, and the cuttings were started in them on July I3. They were as uniform as possible, and their weights varied between 3.5 and 4.5 grammes.

The roots were collected and weighed separately, ten cuttings being taken on each date.

The first roots were removed on July 22 and the last set were weighed on September 7.

The culture solutions were renewed at intervals. The mean weights and probable errors are given in the following table, and the results are plotted in Fig. 2.

Table II. Tradescantia, Series II (see Fig. 2).

$\begin{array}{ccc}\begin{array}{c}\text { Number of } \\ \text { days' }\end{array} \text { growth. } & \begin{array}{c}\text { Mean weight of } \\ \text { wet roots. } \\ \text { grm. }\end{array} & \begin{array}{c}\text { Mean weight of } \\ \text { dry roots. }\end{array} \\ \text { grm. } \\ 9 & 0.08 \pm 0.01 & 0.005 \pm 0.001 \\ \text { II } & 0.14 \pm 0.03 & 0.008 \pm 0.00 \mathrm{I} \\ \text { I3 } & 0.19 \pm 0.05 & 0.010 \pm 0.002 \\ \text { I } 4 & 0.22 \pm 0.04 & 0.012 \pm 0.001 \\ 15 & 0.32 \pm 0.05 & 0.017 \pm 0.001 \\ \text { I7 } & 0.31 \pm 0.04 & 0.016 \pm 0.002 \\ 21 & 0.43 \pm 0.04 & 0.024 \pm 0.002 \\ 24 & 0.64 \pm 0.06 & 0.03 \pm \pm 0.003 \\ 34 & 0.75 \pm 0.09 & 0.038 \pm 0.004 \\ 45 & 0.89 \pm 0.11 & 0.043 \pm 0.006 \\ 56 & 0.84 \pm 0.13 & 0.042 \pm 0.009\end{array}$

In this series the secondary roots were first observed on July 26 and 
were apparent on all roots by July 27. On August 6, after 24 days' growth, the first signs of tertiary roots were visible on most of the plants.

Series III. These experiments were carried out under the same conditions as Series II, only that the cuttings belonged to two groups, 45 cuttings having a mean weight of $5 \mathrm{grm}$., and 45 of $2.5 \mathrm{grm}$. No roots were removed until after 50 days. The series was started on August 19 and the first roots collected on October 8. Only five cuttings were taken each time, from each set, so the probable error is larger, but the experiment was primarily intended to show the effect of the original mass of the cutting on the later part of the growth curve.

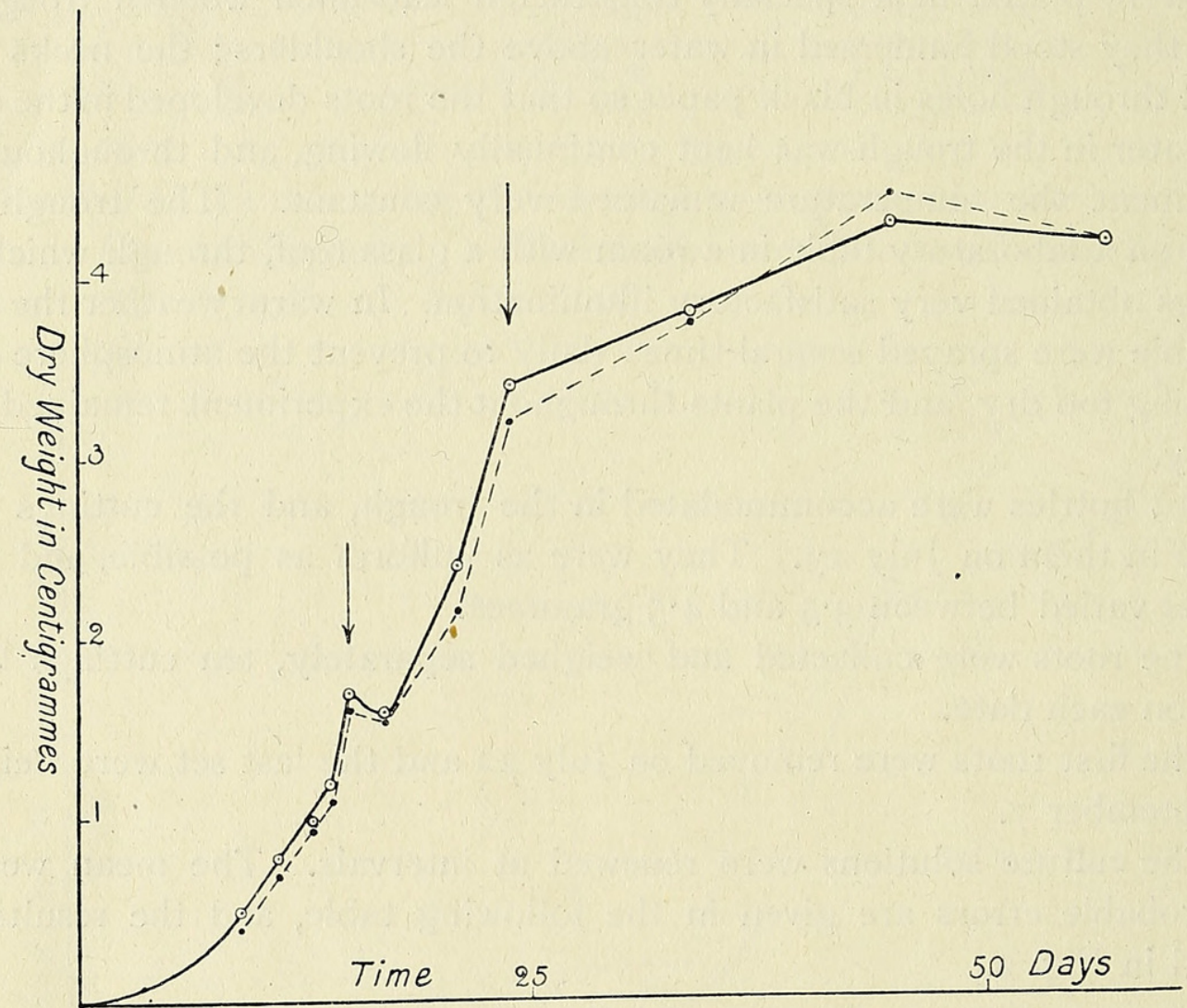

FIG. 2. The growth of roots on Tradescantia cuttings (dry weight). The broken line gives wet weight determinations. Arrows show when secondary and tertiary roots appeared.

On October 8 the roots on the heavier set of cuttings had already developed small tertiary roots, but no signs of them were visible in the small set until October I5. Reference to the table and curve shows two points:

I. That the appearance of the tertiary roots in the $2.5 \mathrm{grm}$. cuttings seems to coincide with a flattening of the $S$ curve (see p. 249).

2. That neither set of roots shows much indication of the development of a third S curve.

The wet weight figures are very irregular, but the dry weight curves suggest a third $S$ curve passing at an early date into a flattened region that continues throughout the winter. Presumably the root production has 
reached a balanced proportion in reference to the shoot production, and during the winter months the shoot production has been small, possibly owing to limiting external conditions.

The final weighings given below seem to indicate that when the roots have reached a steady weight the weight bears a rough proportion to the original weight of the cuttings. This correlation is not so well marked as in Loeb's experiments on regeneration in Bryophyllum ( 6 and 7 ), but his data were obtained in a much shorter time. In these Tradescantia experiments the growth over the period of the experiment was slow, and probably time permitted the smaller cuttings to gain in total mass as compared with the larger ones.

\section{Table PII. Tradescantia, Series III.}

$\begin{array}{ccc}\begin{array}{r}\text { Number of } \\ \text { days' growth. }\end{array} & \begin{array}{c}\text { Tradescantia, } 2.5 \text { grm. } \\ \text { Mean weight of } \\ \text { wet roots. } \\ \text { grm. }\end{array} & \begin{array}{c}\text { Mean weight of } \\ \text { dry roots. }\end{array} \\ & 0.569 & \text { grm. } \\ 50 & 0.677 & 0.030 \\ 57 & 0.714 & 0.035 \\ 64 & 0.647 & 0.037 \\ 71 & 0.547 & 0.039 \\ 78 & 0.612 & 0.035 \\ 95 & 0.655 & 0.036 \\ 106 & 0.618 & 0.035 \\ 148 & 1.357 & 0.036 \\ 300 & & 0.079\end{array}$

$\begin{array}{cc}\begin{array}{c}\text { Tradescantia, } \\ \text { Mean weight of }\end{array} & \begin{array}{c}\text { Mean weight of } \\ \text { wet roots. }\end{array} \\ \text { grm. } & \text { dry roots. } \\ 0.753 & \text { grm. } \\ 0.946 & 0.039 \\ 0.851 & 0.049 \\ 0.953 & 0.046 \\ 0.874 & 0.055 \\ 0.944 & 0.055 \\ 0.763 & 0.056 \\ 0.777 & 0.054 \\ 1.573 & 0.056 \\ & 0.095\end{array}$

\section{Experiments with Tomato.}

The cuttings, taken from two varieties of tomato, varied much in size, as it was found impossible to accumulate a large enough number of cuttings of equal mass at the start of the experiment. For this reason the figures in the table are given as the ratio of the wet or dry weight of the roots to the original weight of the cutting.

The cuttings were grown singly, in inverted flower-pots which stood in dishes of tap-water. There were fifty cuttings of each variety, and five of each were collected at intervals. The experiment was started on July I 5 , and indications of roots were visible on most of the cuttings by July 20. In the 'Sunrise' series, secondary roots began to appear after eighteen days, but in the 'Princess of Wales' not until after twenty days.

The yield of roots was not so regular from cuttings of great original variability in size, and we have no evidence that root production would show any strict proportion to the original mass of the cutting. The probable errors are not given in the table, but are so large that these results, if they stood alone, would have no value. However, they may be regarded as supplying some indication (when the curves in Figs. 5 and 6 are examined) of the same relationship with regard to the rate of growth, and the production of secondary roots, in the case of the tomato as in the case of Tradescantia. 
DRY WEIGHT



FIG. 3. The production of roots on Tradescantia cuttings of initially different weights5.0 and $2.5 \mathrm{grm}$. The arrows show when tertiary roots appeared.

\section{TABLE IV. Tomato ('Sunrise').}

Number of days' growth.

I 2
I3
I 5
I 8
20
22
26
29
32
39

Mean wet ratio.

$$
\begin{aligned}
& 0.037 \\
& 0.069 \\
& 0.045 \\
& 0.402 \\
& 0.327 \\
& 0.426 \\
& 0.502 \\
& 0.619 \\
& 0.791 \\
& 0.440
\end{aligned}
$$

Mean dry ratio.

$$
\begin{aligned}
& 0.0036 \\
& 0.0053 \\
& 0.0060 \\
& 0.28 \\
& 0.024 \\
& 0.030 \\
& 0.039 \\
& 0.039 \\
& 0.051 \\
& 0.038
\end{aligned}
$$

TABle V. Tomato ('Princess of Wales').

Number of days' growth.
Mean wet ratio.

$$
\begin{aligned}
& 0.024 \\
& 0.097 \\
& 0.259 \\
& 0.418 \\
& 0.575 \\
& 0.393 \\
& 0.578 \\
& 1.019 \\
& 1.043 \\
& 0.633
\end{aligned}
$$

Mean dry ratio.

$$
\begin{aligned}
& 0.003^{2} \\
& 0.007 \\
& 0.025 \\
& 0.038 \\
& 0.041 \\
& 0.031 \\
& 0.045 \\
& 0.067 \\
& 0.066 \\
& 0.050
\end{aligned}
$$




\section{INTERPRETATION OF EXPERIMENTAL RESUlts.}

If the curves obtained in all these series of quantitative observations on root growth are compared, it will be seen that they are of one general type, which we venture to describe as a progressive series of $S$ curves. The $S$ curve is of frequent occurrence, when quantitative data of the progress of growth are recorded, both in the case of animals (Robertson (8)) and of plants (Gregory (4), Schuepp (9), \&c.).

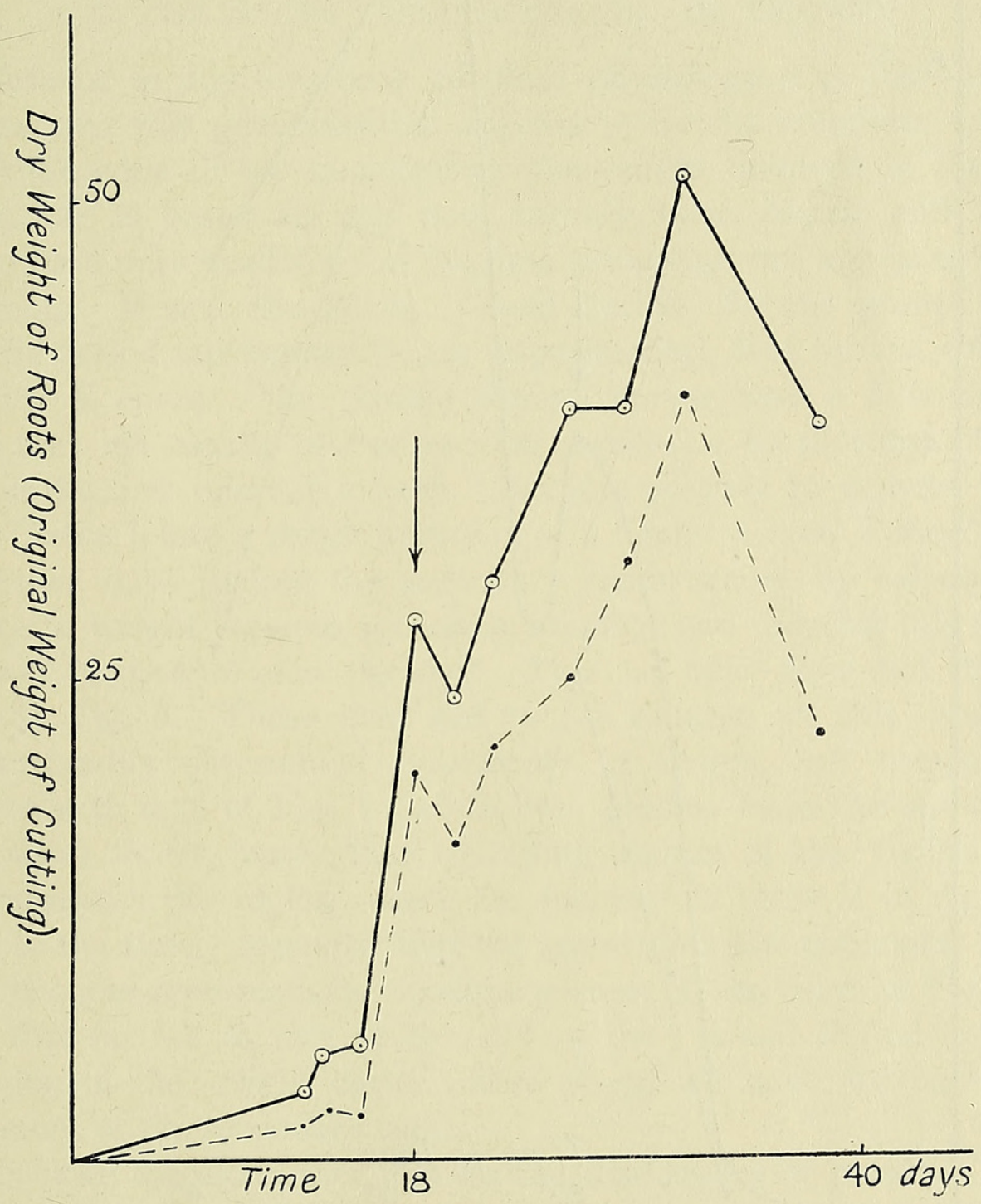

FIG. 4. 'Diy weight ratio' of roots on cuttings of 'Sunrise' tomato (see Table $4 a$ ). The arrow indicates the time of appearance of secondary roots.

A full discussion of this curve will appear in the second paper of this series, so we shall confine ourselves now to two observations which are directly relevant to this special case of the appearance of the $S$ curve in the growth of roots. At the beginning, the cuttings were all rootless, therefore the curve starts at the origin, and indicates an increasing rate of growth which is connected exponentially with time. Subsequently the rate of 
growth falls, and a relatively long straight part of the curve indicates a direct proportion between growth and time. Finally the curve is inflected and growth decreases exponentially with time until a brief almost flat portion terminating the first $S$ curve suggests a temporary cessation of growth.

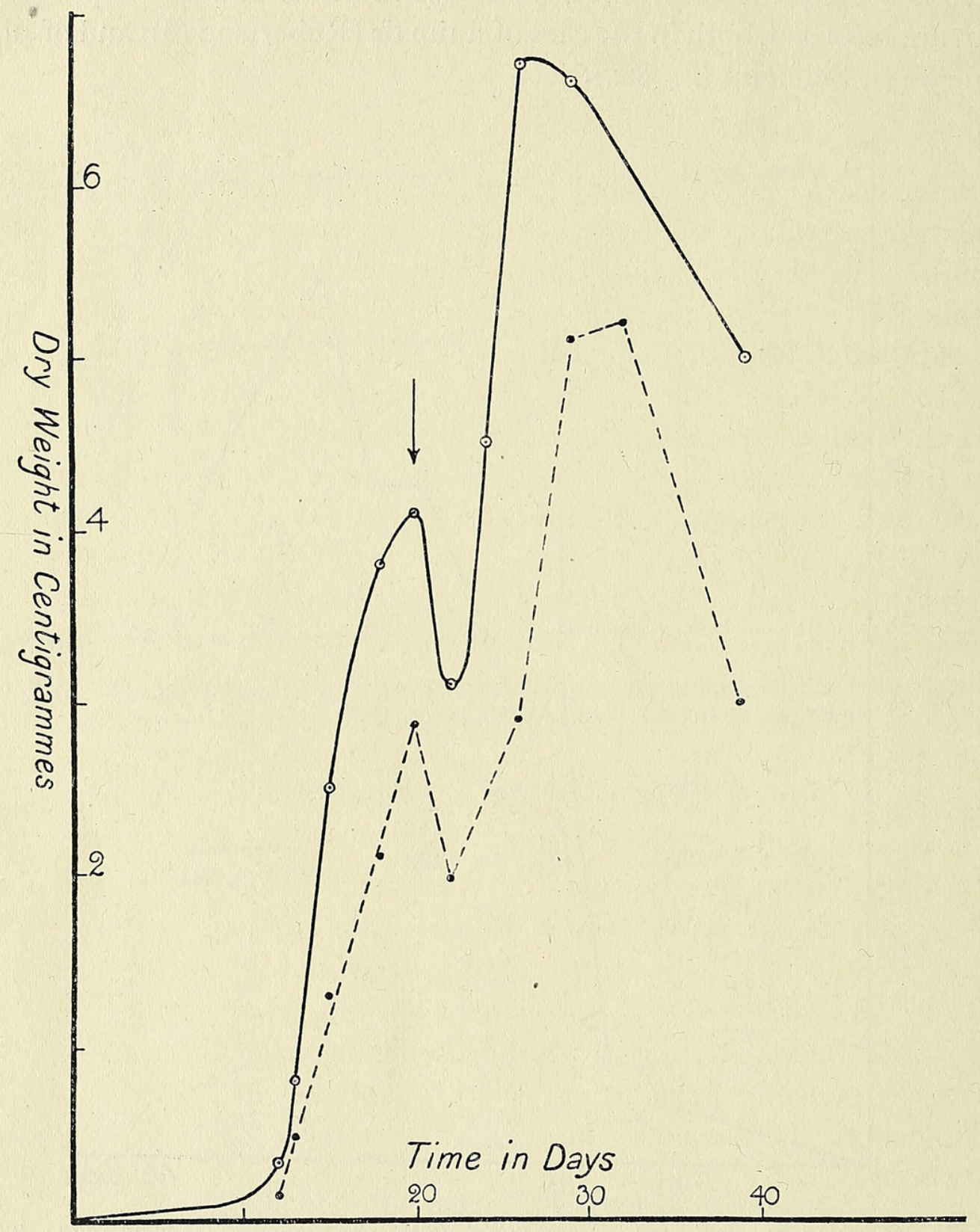

FIG. 5. The dry weight ratio for roots from cuttings of 'Princess of Wales' tomato. The arrow indicates the time of appearance of secondary roots.

We would draw attention to the fact that this last flat region of the curve has obviously some connexion with the development of the lateral roots. In all the curves the point is marked upon the time axis where the occurrence of secondary or tertiary roots was noticed. These points are very definite, especially in the case of Tradescantia, where the lateral roots 
appear on the 14th day. It will be seen that the termination of the first $\mathrm{S}$ curve coincides with the appearance of secondary roots, and the termination of the second $S$ curve with the appearance of tertiary roots (Figs. I, 2, 5, 6). The theoretical discussion of this phenomenon will be reserved for the second paper of this series.

The second point that emerges is that this $\mathrm{S}$ curve, in so far as it applies to roots, is a restatement of the Sachs 'Grand Period' of Growth.

\section{The Sachs 'Grand Period' of Growth.}

Reference to any text-book of plant physiology (e.g. Jost (5), p. 288) will show that this generalization appears to be the complete expression of our knowledge of the quantitative phenomena involved in the growth of roots. It is based up till now entirely upon length, and therefore these data are only available for the time preceding the appearance of the lateral roots. Hence, the Sachs 'Grand Period' for the growth of roots covers the period represented in our experimental data by the completion of the first $\mathrm{S}$ curve. The 'Grand Period' curves have a different shape, because they are usually plotted as rate curves (i.e. by plotting changes in length in the time intervals taken). But it is possible to convert the data given in Table I into a rough imitation of a Sachs 'Grand Period', for the first fourteen days (before the secondary roots occur), by calculating the difference in weight between successive readings and reducing this to a relative rate of increase of mass per day. This has been done and the results plotted in Fig. 6. These data are not so suitable for this treatment as the more readily determined increments in length, but comparison of this curve with that of Fig. I (which was plotted from the same experimental data) shows, firstly, that the rising section of the 'Grand Period' curve represents the region where the increase in mass is in exponential relation to the time; secondly, that the approximately horizontal region of the Sachs curve represents the straight portion of the curve in Fig. I ; and, thirdly, that the fall in rate at the end of the 'Grand Period' represents that region of the weight curve whose shape we have attributed to the development of the secondary roots.

It is clear, therefore, that, but for the inadequacy of previous methods of measurement, it would have been possible to demonstrate in the growth of roots (at any rate when produced upon cuttings) a series of 'Grand Period' curves. Each one of these represents the period between the origin of one crop of lateral roots and the appearance of a succeeding crop of rootlets arising from this first batch.

The significance of this statement will be considered further in the next paper of this series.

Presumably this type of curve, the S curve or 'Grand Period' curve, will occur until the root mass is in equilibrium with the mass of the leaf and 
shoot, when the subsequent curve of growth may be expected to merge into that characteristic of the sum of the activities of the plant.

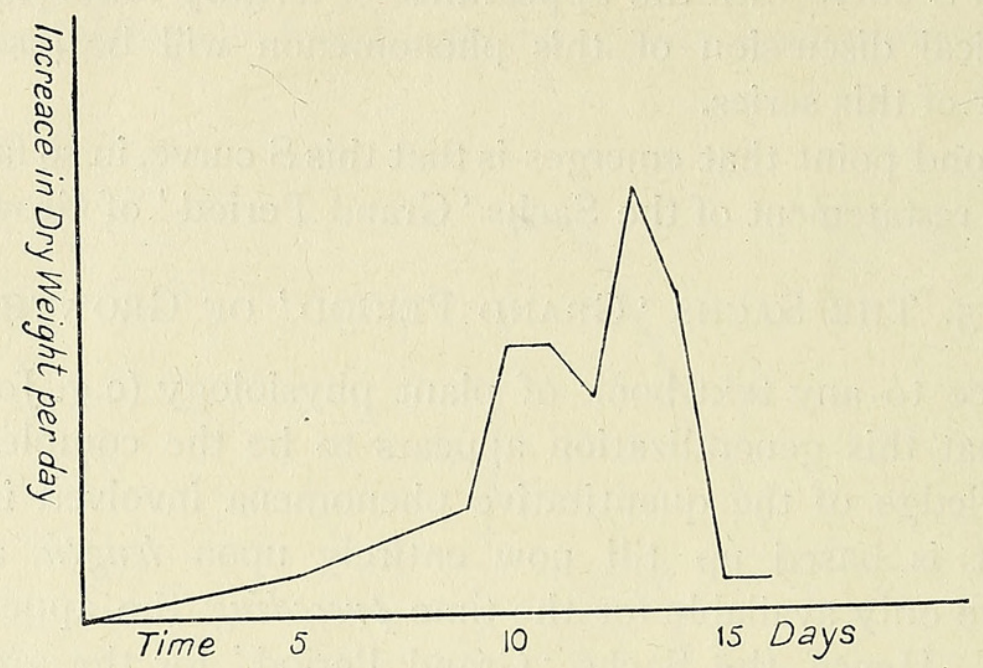

FIG. 6. The data of Table I plotted as a rate-curve showing Sachs's 'Grand Period ' of growth. The first part of the curve is suggested.

\section{Summary.}

I. The data obtained in some quantitative studies of root growth are presented in the form of tables and curves.

2. Roots were chosen, in these experiments, to avoid the more direct influence of the progressive change in photosynthetic area during growth.

3. Cuttings were used, instead of seedlings. In the case of Tradescantia, the cuttings were of uniform weight.

4. When plotted, the data provide examples of successive curves of the characteristic $S$ type so frequently found in growth experiments.

5. The time of transition from one $S$ curve to the next is shown to coincide with the time of appearance of a crop of rootlets of subordinate branch order.

6. It is pointed out that a single $\mathrm{S}$ curve corresponds to the Sachs 'Grand Period' curve for root growth, and that if his method of measurement had permitted, the rate of growth of roots would have provided a series of such 'Grand Period' curves.

\section{REFERENCES.}

1. Blackman, V. H.: The Compound Interest Law and Plant Growth. Ann. Bot., xxxiii. $353-60,1919$.

2. Brenchley, Winifred : On the Relations between Growth and the Environmental Conditions of Temperature and Bright Sunshine. Ann. of App. Biol., vi. 2 I I-44, 1920.

3. Briggs, G. E., Kidd, F., and West, C. : A Quantitative Analysis of Plant Growth. Ann. of App. Biol., vii. $103^{-2} 3$ and $202-23,1920$. 


\section{Priestley and Evershed.-Growth Studies. I.}

4. Gregor y, F. G.: The Increase in Area of Leaves and Leaf Surface of Cucumis sativus. Ann. Bot., xxxv. 93-123, I92I.

5. Jost : Plant Physiology, translated by Gibson. Oxford, 1907.

6. Loeb, J.: The Law controlling the Quantity of Regeneration in the Stem of Bryophyllum calycinum. Journ. of Gen. Physiol., i. 8I-96, I9เ8.

7. — : Quantitative Laws in Regeneration. I and II. Journ. of Gen. Physiol., ii. 297-308 and $65 \mathrm{I}-8$.

8. Robertson, T. BrailsFord: On the Normal Rate of Growth of an Individual and its Biochemical Significance. Archiv für Entwicklungsmechanik der Organismen, xxv. 58I$61_{4}, 1908$.

9. Schuepr, Отto: Wachstum und Formwechsel des Sprossvegetationspunktes der Angiospermen. Ber. der deutsch. Bot. Ges., xxxii. 328-39, I914.

10. Shive, J. W. : A Study of Physiological Balance in Nutrient Media. Physiological Researches, i. $327-97$, I9I 5 .

11. West, C., Briggs, G. E., and Kidd, F. : Methods and Significant Relations in a Quantitative Analysis of Plant Growth. New Phytologist, xix. 200, 1920.

12. Wood, T. B.: The Interpretation of Experimental Results. Supplement No. 7 to Journ. of Board of Agric., Nov. I9II. 


\section{$2 \mathrm{BHL}$ Biodiversity Heritage Library}

Priestley, J. H. and Evershed, A. F. C. H. 1922. "Growth studies. I. A quantitative study of the growth of roots." Annals of botany 36, 225-237. https://doi.org/10.1093/oxfordjournals.aob.a089795.

View This Item Online: https://www.biodiversitylibrary.org/item/234428

DOI: https://doi.org/10.1093/oxfordjournals.aob.a089795

Permalink: https://www.biodiversitylibrary.org/partpdf/319038

\section{Holding Institution}

Smithsonian Libraries

\section{Sponsored by}

Biodiversity Heritage Library

\section{Copyright \& Reuse}

Copyright Status: Not in copyright. The BHL knows of no copyright restrictions on this item.

This document was created from content at the Biodiversity Heritage Library, the world's largest open access digital library for biodiversity literature and archives. Visit BHL at https://www.biodiversitylibrary.org. 